\title{
EARLY PASSENGER LEUKOCYTE MIGRATION AND ACUTE IMMUNE REACTIONS IN THE RAT RECIPIENT SPLEEN DURING LIVER ENGRAFTMENT: WITH PARTICULAR EMPHASIS ON DONOR MAJOR HISTOCOMPATIBILITY COMPLEX CLASS II $^{+}$CELLS $^{1}$
}

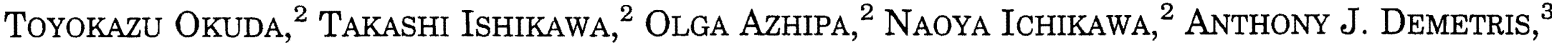 \\ ThOMAS E. STARZL, ${ }^{2}$ AND NORIKo MURASE ${ }^{2,4}$
}

Thomas E. Starzl Transplantation Institute, Departments of Surgery and Pathology, University of Pittsburgh Medical Center, Pittsburgh, Pennsylvania

\begin{abstract}
After a short course of tacrolimus, Lewis rat liver allografts induce donor-specific nonreactivity in Brown Norway recipients that is immunosuppressionindependent after 28 days. To clarify the role of donor major histocompatibility complex (MHC) class $\mathrm{II}^{+}$ cells, we investigated the migration to the recipient splenic $T$ - and B-cell compartments of different subsets of Lewis MHC class $\mathrm{II}^{+}$passenger leukocytes. The rise and decline of immune activation were monitored in the hepatic allograft and in the host spleen by analyses of BrdU ${ }^{+}$(proliferating) leukocytes, TUNEL ${ }^{+}$(apoptotic) cells, apoptosis-associated molecules, TH1/ TH2 cytokine profiles, and histoimmunocytochemical examination of graft and splenic tissues. Serial flow cytometry studies during the 28-day period of drugassisted "hepatic tolerogenesis" showed that migratory MHC class $\mathrm{II}^{+}$cells accounted for less than half of the donor cells in the host spleen. The class $\mathrm{II}^{+}$cells consisted mostly of $B$ cells that homed to splenic B-cell follicles with only a sparse representation of dendritic cells that were exclusively found in the splenic periarteriolar lymphoid sheath. In parallel studies, transplantation of the less tolerogenic heart produced a diminutive version of the same events, but with far fewer donor cells in the host spleen, evidence of sustained immune activation, and the development of chronic rejection by 100 days. The data are consistent with the paradigm that migration of donor leukocytes is the prime determinant of variable tolerance induction induced by transplantation of the liver and other organs, but without regard for donor $\mathrm{MHC}$ class $\mathrm{II}^{+}$ expression.
\end{abstract}

\section{INTRODUCTION}

It has been described $(1,2)$ how organ alloengraftment occurs as the result of "responses of co-existing donor, that is, passenger leukocytes, and recipient immune cells, each to the other, causing reciprocal clonal expansion followed by periph-

\footnotetext{
${ }^{1}$ Supported by the National Institutes of Health grants DK 29961, RO1 AI/DK 38899, and DK 54232.

${ }^{2}$ Department of Surgery.

${ }^{3}$ Department of Pathology.

${ }^{4}$ Address correspondence to: Noriko Murase, MD, Thomas E. Starzl Transplantation Institute, Department of Surgery, E1555 Biomedical Science Tower, University of Pittsburgh, Pittsburgh, PA 15213.

Received 4 September 2001. Revision Requested 15 November 2001. Accepted 4 February 2002.
}

eral clonal exhaustion" $(3,4)$. The persistence in the host of donor passenger leukocytes above some threshold required to maintain the clonal exhaustion-deletion induced acutely by the migratory donor cells is a necessary condition for long organ allograft survival (1-5). The variable deletional tolerance of the double-immune response evolves spontaneously in some experimental models (6-9), especially when the transplanted organ is the liver $(6,7,10,11)$. Immunosuppression usually is required to prevent one immune cell population from destroying the other before the reciprocal deletion can occur.

This paradigm has been controversial (12-15), in part because it is incompatible with numerous competing hypotheses of organ engraftment $(1,2)$. For example, the migratory donor cells found in recipient tissues early and late after organ transplantation include major histocompatibility complex (MHC) class $\mathrm{II}^{+}$dendritic cells (DC) $(3-5,11,16-18)$ that have been associated historically with protective immunity (that is, rejection) rather than immune nonreactivity or tolerance (19-22). We studied the donor MHC class $\mathrm{II}^{+}$cells in a rat liver transplant model in which donor-specific tolerance develops over a period of 1 month under an umbrella of tacrolimus (TAC) immunosuppression. In addition to serial donor leukocyte determinations in the liver allograft and host spleen during the 4-week period of tolerogenesis, cytokine and other parameters that reflect the rise and decline of immune activation were analyzed in the same locations. When appropriate, the findings were compared with those after transplantation of the less tolerogenic heart under identical treatment conditions. The results undermine the widely held view that the expression (or nonexpression) of $\mathrm{MHC}$ class II of the migratory donor leukocytes is a crucial determinant of outcome after organ transplantation.

\section{MATERIALS AND METHODS}

\section{Animals and Transplantation Procedures}

Male Lewis (LEW, RT1 ${ }^{1}$ ) and Brown Norway $\left(\mathrm{BN}, \mathrm{RT} 1^{\mathrm{n}}\right)$ rats weighing 150-250 g (Harlan Sprague Dawley, Indianapolis, IN) were maintained in a specific pathogen-free environment at the University of Pittsburgh and used as donors and recipients, respectively. Heterotopic abdominal heart transplantation (HTx) and orthotopic liver transplantation (OLTx) (portal revascularization only) were carried out as previously described (5), according to the guidelines of the Council on Animal Care at the University of Pittsburgh. 


\section{Immunosuppression}

The naive BN heart and liver recipients were administered TAC (FK 506, Fujisawa Pharmaceutical Co., Osaka, Japan) at a daily intramuscular (IM) dose of $1.0 \mathrm{mg} / \mathrm{kg}$ on days $0-13$, with single supplemental injections of the same dose on days 20 and 27.

\section{Experimental Design}

Cohorts of recipients were killed and autopsied on posttransplant days $1,3,5,7,14$, and 28 . The allograft and the host spleen were sectioned and fixed in $10 \%$ neutral-buffered formalin for routine histopathology, embedded in optimum cold temperature compound (Tissue-Tek, Ames Division, Miles Laboratories, Inc., Elkhart, IN) for immunohistochemical studies, and snap-frozen in liquid nitrogen for mRNA extraction. In addition, recipient spleen was used for flow cytometry. Several heart and liver recipients were kept for 100 days and killed for histopathological analysis of chronic rejection (CR) in the allografts and for collection of cervical lymph nodes for mixed lymphocyte reaction (MLR) assays.

\section{Routine Histopathology of Allografts}

Formalin-fixed heart and liver allografts were embedded in paraffin, sectioned at $4 \mu \mathrm{m}$, and stained with hematoxylin-eosin. In heart allografts, the overall severity of inflammation in the endocardium, pericardium, interstitium, and periarterial spaces was semiquantitatively graded on the scale of $0-4$ as none, minimal, mild, moderate, or severe (23). Arterial alterations, including the presence of inflammation, edema, fibrosis, and vacuolation of the intima, media and adventitia were graded in the same way. In addition, the total number of arteries more than $80 \mu \mathrm{m}$ present in cross-section was recorded to assure a similar sampling between animals and graded for obliterative arteriopathy (OA).

Histopathological changes in the liver allografts were evaluated as the presence of bile duct damage and/or loss, bile ductular proliferation, the presence of subendothelial mononuclear infiltration in the portal or central veins, and severity of portal tract inflammation.

\section{Immunohistopathological Analyses}

Portions of allograft and recipient spleen were sectioned at $4 \mu \mathrm{m}$ and stained with a routine indirect avidin-biotin complex method or immunofluorescence technique (24). Biotinylated or Cy3-conjugated monoclonal antibody (mAb) L21-6 (mouse $\operatorname{IgG}_{1}$ ), which reacts with the class II MHC antigens of LEW (donor) but not BN (recipient) (25), was used to detect donor $\mathrm{MHC}$ class $\mathrm{II}^{+}$cells. The number of L21 $-6^{+}$donor cells was counted in 20 randomly selected high power fields (HPF; $\times 400$ magnification). Isotype-matched nonspecific antibody was substituted for mAb L21-6 in negative controls.

Other mAbs used in this study included R7.3 ( $\alpha \beta T C R$ ), ED1 (infiltrative macrophages), ED2 (tissue macrophages), anti-rat IgM (B cells), OX33 (CD45RA, B cells), OX8 (CD8 $)$, and 8A2 (CD11c, DC). Most of these lineage-specific mAbs were conjugated with fluorescein (PharMingen, San Diego, CA and Serotec, Kidlington, Oxford, UK). For unconjugated $\mathrm{mAb}$, fluorescein-conjugated goat anti-mouse IgG was used as a secondary antibody.

\section{Cell Proliferation and Apoptosis}

Animals were given an intravenous (IV) injection of $50 \mathrm{mg} / \mathrm{kg}$ 5-bromo-2'-deoxyuridine (BrdU, Sigma, St. Louis, MO) 1 hour before death. The labeled cells were detected with an anti-BrdU mAb (Amersham Life Science Inc., Cleveland, $\mathrm{OH}$ ) using routine indirect immunoperoxidase staining. The number of lymphocytes undergoing DNA synthesis (in $\mathrm{S}$-phase) was determined by counting the number of $\mathrm{BrdU}^{+}$lymphocytes in 20 randomly selected HPF $(\times 400)$.

The terminal deoxynucleotidyl transferase-mediated biotin-dUTP nick end labeling (TUNEL) method using Apop Tag kit (Intergen, Purchase, NY) localized apoptotic cells in the same paraffin blocks used for the BrdU DNA synthesis detection. Positively stained cells were counted in 20 randomly selected HPF (see above).

\section{Flow Cytometry}

Splenocytes were prepared by mincing a piece of spleen and lysing the red blood cells. Splenocytes were analyzed by two-color flow cytometry using affinity purified biotinylated mAbs 163 (rat IgG2b) and 42 (rat IgG2a), specific for the RT1.A ${ }^{1}$ (LEW MHC class I antigen) and the RT1.A ${ }^{\mathrm{n}}$ (BN MHC class I antigen), respectively (26). Cychrome-conjugated streptavidin (PharMingen) was applied as a secondary antibody. Lineage-specific fluorescein-conjugated mAbs (see above) were used for double stain.

\section{RNA Preparation and RNase Protection Assay (RPA)}

Total RNA was extracted from frozen samples by using TRIZOL Reagent (Life Technologies, Grand Island, NY) according to the manufacturer's instructions. The concentration of RNA was determined by UV spectrophotometer at $260 \mathrm{~nm}$. An RNase protection assay (RPA) using commercially available kits (PharMingen) was used to quantify cytokine mRNA production. Radiolabeled antisense RNA multiple probes were synthesized using in Vitro Transcription Kit and rat cytokine multiprobe template sets (rCK-1 and rAPO-1, PharMingen), which included probes for cytokines [interleukin (IL)$1 \alpha$, IL-1 $\beta$, IL-2, IL-3, IL-4, IL-5, IL-6, IL-10, tumor necrosis factor (TNF)- $\alpha$, TNF- $\beta$, and interferon (IFN) $\gamma$ ], apoptosis-associated molecules (Fas, FasL, caspase-1, 2, 3, bcl-X, bcl-2, and bax), respectively, and housekeeping genes (L32 and GAPDH).

${ }^{32} \mathrm{P}$-labeled probes $\left(8.0 \times 10^{5} \mathrm{cpm}\right)$ and sample RNA (5 $\left.\mu \mathrm{g}\right)$ were hybridized at $56^{\circ} \mathrm{C}$ for $12-16$ hours and single-stranded RNAs including antisense RNA probes were digested by using RPA Kit (PharMingen). The protected RNA duplexes-were isolated by RNase inactivation/precipitation solution (Ambion Inc., Austin, TX), and electrophoresed in a standard sequencing gel. Dried gels were exposed to Storage Phosphor Screen (Molecular Dynamics, Sunnyvale, CA) for 12 hours at room temperature. The radioactivity of each band was measured by $\beta$-scan (PhosphorImager, Molecular Dynamics) and NIH Image analysis software. The results were normalized to GAPDH and expressed as a ratio of cytokine or apoptotic signal/GAPDH.

\section{Mixed Lymphocyte Reaction}

One-way MLR assayed antidonor reactivity of $B N$ recipients, in vitro (5). Responder cervical lymph node lymphocytes $\left(1.75 \times 10^{5}\right)$ obtained from BN recipients 100 days after HTx or OLTx and irradiated $(2000 \mathrm{rad})$ stimulator cells $\left(3 \times 10^{5}\right)$ were combined in a final volume of $0.2 \mathrm{~mL}$ RPMI supplemented with $25 \mathrm{mM}$ HEPES buffer, $5 \times 10^{-5} \mathrm{M} 2$-mercaptoethanol, $2 \mathrm{mM}$ L-glutamine, $50 \mathrm{U} / \mathrm{ml}$ penicillin, $50 \mu \mathrm{g} / \mathrm{ml}$ streptomycin, $\mathrm{N}^{\mathrm{G}}$-monomethyl-L-arginine-HOAc (Cyclo ${ }_{3}$ pss Biochemical Co., Slake Lake, UT) and 10\% heat-inactivated normal rat serum. Triplicate cultures were incubated in a humidified atmosphere of $5 \% \mathrm{CO}_{2}$ in air for 5 days at $37^{\circ} \mathrm{C}$. One $\mu \mathrm{Ci}$ of ${ }^{3} \mathrm{H}$-thymidine was added to each well 16 hours before the termination of the culture. Cultures were harvested with multiple sample harvester and ${ }^{3} \mathrm{H}$-thymidine uptake was determined by liquid scintillation.

\section{Statistical Analysis}

All results were expressed as mean \pm SD. Numbers of positively stained cells in tissue sections and mRNA levels in RPA assays were analyzed by one-way factorial analysis of variance. Fisher's PLSD test assessed the statistical difference between groups. Student's $t$ test was used for the analyses of MLR. $P$ less than 0.05 was considered significant.

\section{RESULTS}

Untreated BN recipients reject LEW heart allografts in 8 days and LEW livers in 23-32 days (median 28.5), although 
all liver and heart grafts survive for 100 days under the 28-day course of TAC. As reported previously (5), however, by 100 days (73 days after the last dose of TAC), the liver allografts were CR free (Fig. 1, right) although the transplanted hearts had severe CR (Fig. 1, left). CR was manifested by endocardial, pericardial, interstititial, and periarterial mononuclear inflammation, and by patchy interstitial fibrosis. The overall inflammation score (23) was $2.8 \pm 1$.1. In addition, OA was recorded in $53.2 \%$ of the vessels examined. The liver allografts at day 100 were essentially normal, except for mild lymphocytic infiltrates in the portal triad and occasional bile duct proliferation indicative of minor biliary complications, presumably related to the lack of an arterial blood supply (Fig. 1, right).

The histopathological findings at 100 days posttransplantation were congruent with the results of MLR studies at the time of death. Antidonor proliferation of cervical lymph node lymphocytes of OLTx recipients was significantly depressed $(P<0.001)$, although the response of comparable cells from 100-day heart recipients was much less reduced $(P=0.068)$ (Fig. 2). Reactivity against third party strain cells (ACI) was fully preserved in both liver and heart recipients.

\section{Serial Cytokine mRNA Levels}

Previous studies of this liver transplant model demonstrated that the evolution of TAC-assisted donor-specific tolerance is complete by 4 weeks after which the liver allograft remains CR-free without immunosuppression $(5,17)$. Cytokine profiles were monitored during the 28-day period of the immunosuppression. The results were compared with those after transplantation under identical treatment of the less tolerogenic (that is, CR-prone) heart allografts.

Levels in the allografts. When no immunosuppression was given, IL-2 and IFN $\gamma$ were progressively up-regulated in both the liver and heart allografts during the first 7 posttrans-

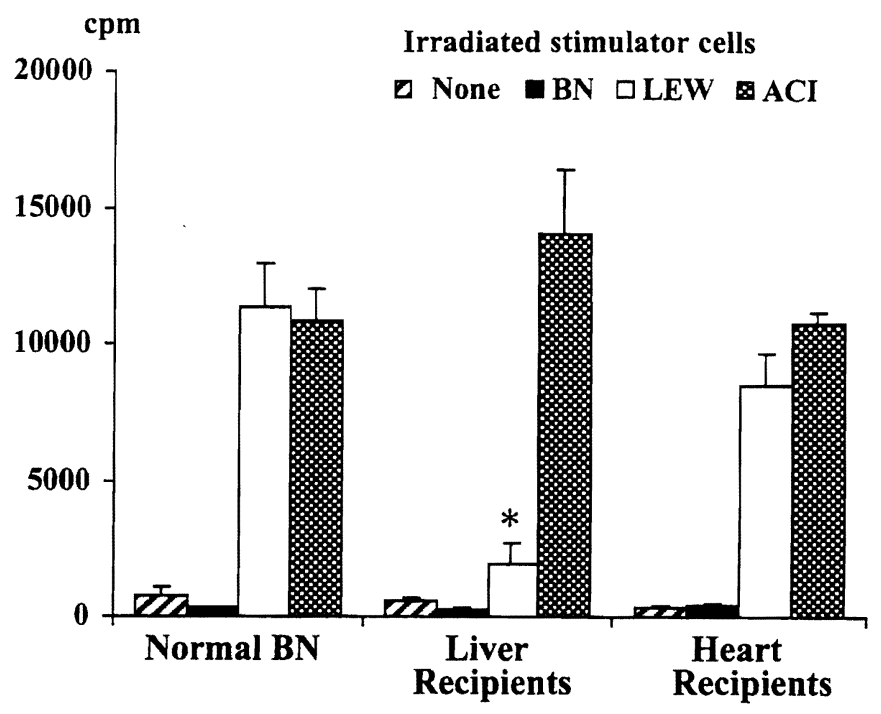

Groups

Figure 2. One-way MLR. One hundred days after LEW to BN heart and liver transplantation under a 28-day course TAC immunosuppression, recipient cervical lymph node lymphocytes were stimulated in MLR with irradiated (20 Gy) LEW (donor), BN (syngenic), and ACI (third party) lymphocytes, using cell-free medium as background control. The LEW-specific proliferative response shown in the third bars of each cluster can be compared with the ACIspecific (that is, third party) response in the fourth bars. Bars 1 and 2 are cell-free medium and syngeneic (BN) stimulator controls. Donor-specific responsiveness was reduced significantly in the liver $(P<0.001$ vs. normal $B N)$, but inconclusively in the heart recipients $(P=0.068)$.

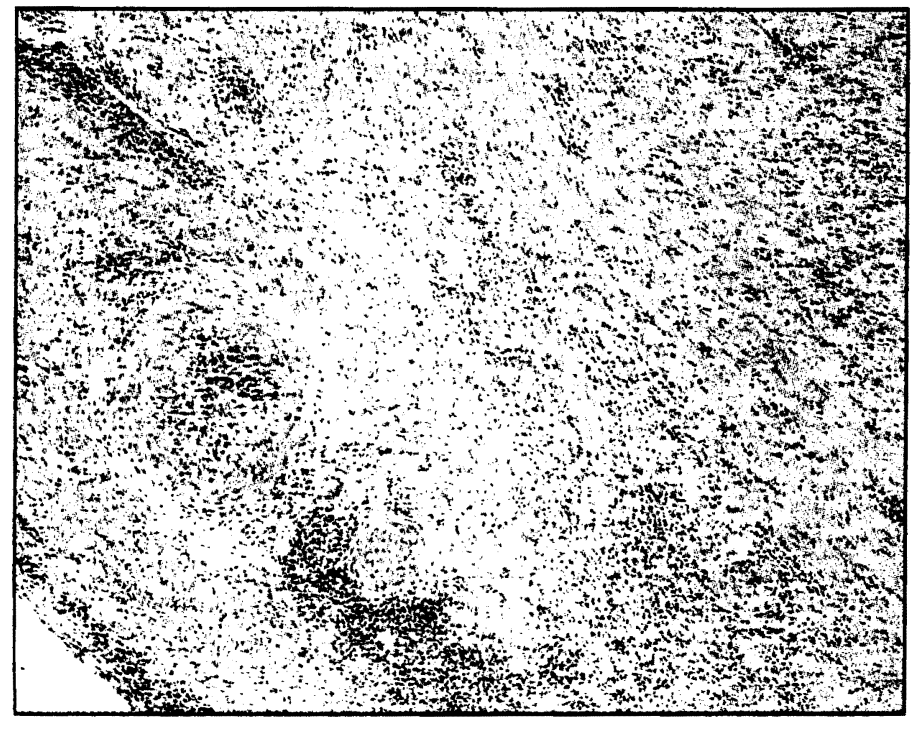

Heart Graft (day100)

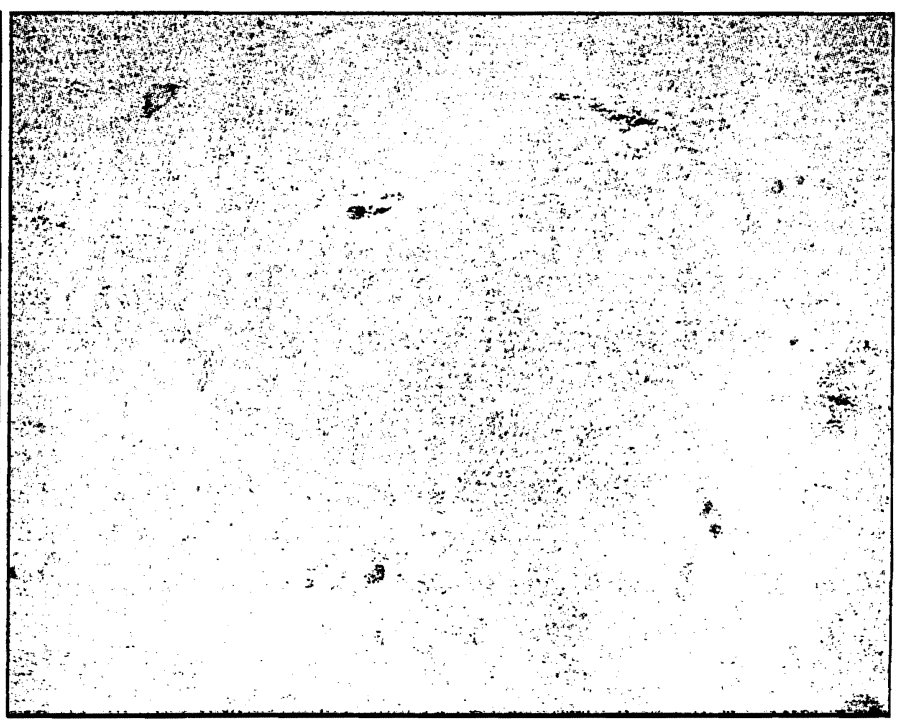

Liver Graft (day100)

FIGURE 1. Routine histopathology of LEW heart (left) and liver (right) allografts 100 days after transplantation to BN recipients under a 28-day course TAC immunosuppression. The liver allograft at day 100 is essentially normal and the heart allograft has severe CR, including inflammatory infiltrates, patchy fibrosis, and obliterative arteriopathy. 
plant days, significantly more so in the hearts (Fig. 3, top). Smaller increases of IL-4 and IL-10 were also observed.

The short course of TAC altered the mixed TH1-TH2 response, mainly by down-regulation of signals for IL-2 and IFN $\gamma$ that was significantly more pronounced in the liver allografts. In addition, a significantly greater increase in mRNA for IL-10 was observed in the TAC-protected liver allografts than in the comparable heart allografts (Fig. 3, bottom).

Levels in host spleens. In untreated liver recipients, and to a significantly lesser extent in unmodified heart recipients, both TH1 (IL-2, IFN $\gamma$ ) and TH2 (IL-4, IL-10) cytokine expression in the recipient spleens was increased. The directional changes were similar to those that occurred in both kinds of organ allografts (compare the top of Fig. 4 with the top of Fig. 3).

TAC treatment resulted in down-regulation in the host spleen of IL-2 and IFN $\gamma$ mRNA, significantly more in liver than in heart recipients (Fig. 4, bottom). The tripling or quadrupling of the TH2 cytokine increases in the spleen (IL-4 and IL-10) were not different under TAC than in animals that were not treated. Of interest, the preferential up-regulation of IL-10 observed in the liver allografts of TAC-treated recipients was not seen in the spleens of these recipients (compare bottom of Figs. 3 and 4).

\section{Proliferation/Apoptosis}

In the allografts. In untreated recipients, proliferating leukocytes (detected by BrdU staining) increased progressively in hearts and livers during the first posttransplantation week (Fig. 5A, top). The proliferation was strongly associated with apoptosis (that is, TUNEL ${ }^{+}$cells) (Fig. 5B, top). However, the apoptotic cells were only one-third to one-half as frequent as the $\mathrm{BrdU}^{+}$cells (compare Fig. $5 \mathrm{~A}$ and $\mathrm{B}$, taking into account the different scales).

Under TAC, the frequency of the $\mathrm{BrdU}^{+}$leukocytes rose initially, but declined and then remained above baseline out
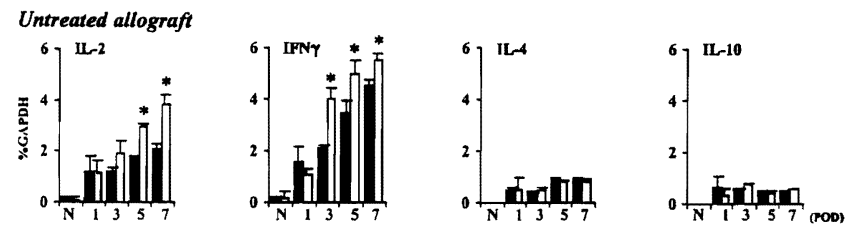

TAC treated allograft
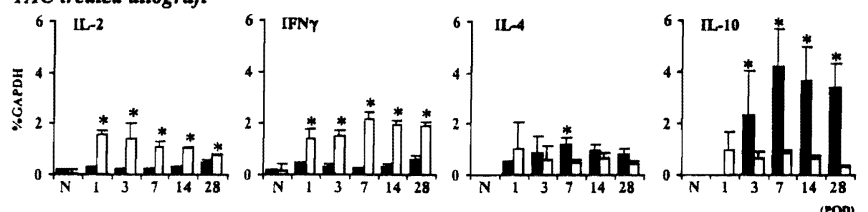

FigURE 3. Serial mRNA for cytokines in the allografts: heart (open bars) and liver (black bars) ( $n=3-6$ at each time point). $* P<0.05$ (liver vs. heart). $N$, Normal heart and liver. Upper panels, Without immunosuppression, there was dramatic upregulation of TH1 cytokines (IL-2, IFN $\gamma$ ) in both kinds of allografts. There also were modest increases (from undetectable) of the TH2 cytokines, IL-4 and IL-10. Lower panels, Under TAC treatment, the TH1 cytokines were down-regulated, much more in liver than the heart allografts. TH2 cytokine changes associated with therapy were limited to upregulation of IL-10 in the liver allografts.
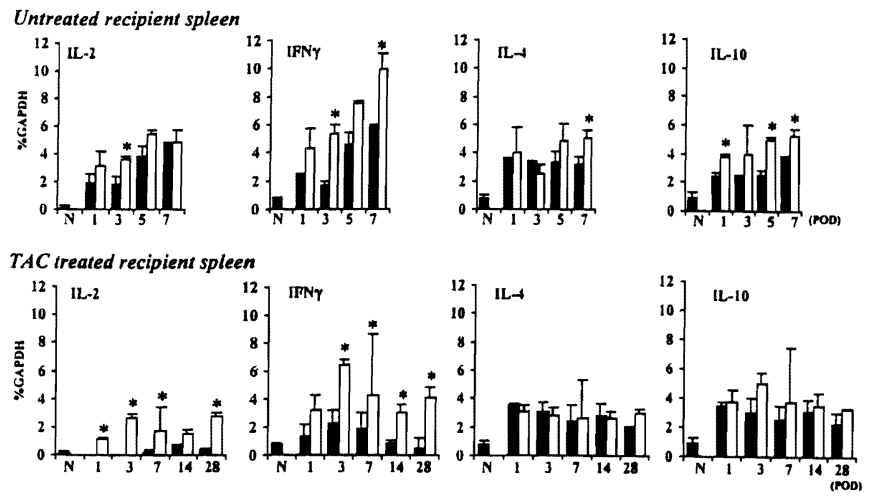

FIgURE 4. Cytokine mRNA in recipient spleen after heart (open bars) and liver transplantation (black bars) (n=3-5 at each time point). ${ }^{*} P<0.05$ (liver vs. heart). $N$, Normal spleen. Top, The cytokine changes in the spleen of untreated recipients roughly paralleled those in the rejecting heart and liver allografts, but were of greater magnitude. (Note the difference in amplitude scale of Fig. 4 compared with Fig. 3.) Bottom, IL-2 and IFN $\gamma$ expression in the spleen was significantly less reduced in TAC-treated heart compared with liver recipients, but there was no demonstrable effect of therapy on the TH2 cytokines. The absence of up-regulation of $\mathrm{LL}-10$ in spleen of the liver recipients was inconsistent with the apparent increase of this cytokine observed in the hepatic allografts (compare Fig. 4, bottom, with Fig. 3, bottom).
(A) BrdU uptake

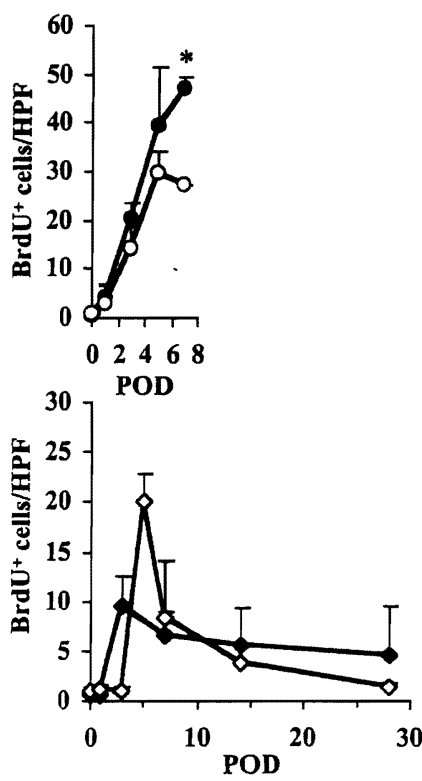

(B) Apoptosis
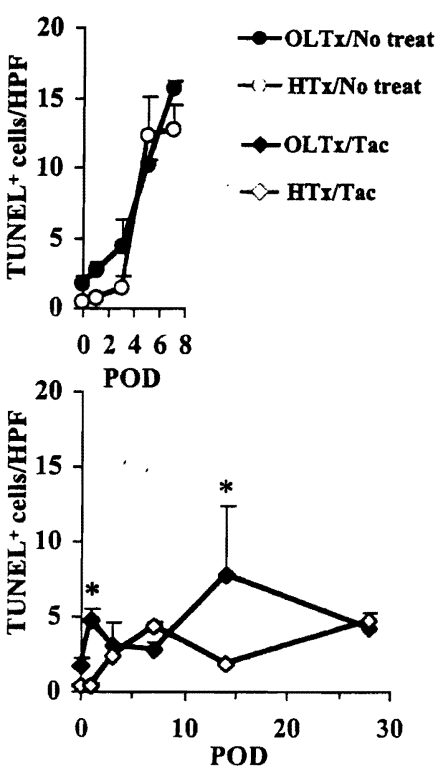

Figure 5. Numbers of (A) BrdU ${ }^{+}$infiltrates and (B) TUNEL $^{+}$ cells in allografts on different postoperative days (POD) after HTx (open bars) and OLTx (black bars) without treatment (top) or under 28-day course of TAC (bottom). $n=3-6$ at each time point. ${ }^{*} P<0.05$ (heart vs. liver).

to 28 days (Fig. $5 \mathrm{~A}$, bottom). In the heart allografts, these cells were mainly in lymphocyte aggregates in the epicardium, pericardium, and periarterial areas. The number of TUNEL $^{+}$(apoptotic) cells increased in rough parallel to the $\mathrm{BrdU}^{+}$cells and at two time points (days 1 and 14), the 
apoptotic cells were significantly more numerous in liver than in heart grafts (Fig. 5B, bottom).

With or without immunosuppression, mRNA for Fas and caspase-3 were significantly more up-regulated in liver than in heart allografts at most time points (Fig. 6).

In host spleens. At day 5 in untreated OLTx recipients, the $\mathrm{BrdU}^{+}$cells rose in the recipient spleens to a peak of $365 \pm 28.4$ cells $/ \mathrm{HPF}$, more than twice the number in the spleens of the heart recipients (Fig. 7A, top). After both liver and heart transplantation, the $\mathrm{BrdU}^{+}$cells/HPF were 5 to 10 times more numerous in the host spleen than the respective allografts [compare Fig. 7A, top (spleen), with Fig. 5A, top (allograft)].

Under TAC therapy, the burst of $\mathrm{BrdU}^{+}$cells in the host spleen after liver as well as heart transplantation was blunted or reversible. The number of positive cells remained elevated throughout the 28 days of immunosuppression (Fig. $7 \mathrm{~A}$, bottom). In parallel with the $\mathrm{BrdU}^{+}$leukocytes, a smaller number of TUNEL ${ }^{+}$(apoptotic) cells were observed in the host spleen after both kinds of transplantations, similar to the $\mathrm{BrdU}^{+} / \mathrm{TUNEL}^{+}$proportions in the allografts (compare Fig. 7B, bottom, with Fig. 5B, bottom). The apoptotic cells in both the host spleen (Fig. 7B, bottom) and the transplanted organ (Fig. 5B, bottom) was greater when the allograft was a liver (significant on days 1 and 14). This observation was supported by the RPA of mRNA for apoptosis-associated molecules that showed greater up-regulation of apoptotic signals in the spleens of TAC-treated liver recipients (Fig. 8). The latter confirmatory evidence was weakened by the limitation of this finding to day 14 .

\section{Immunohistopathological Studies of Host Spleen}

Donor MHC class $\mathrm{II}^{+}\left(\mathrm{L} 21-6^{+}\right)$cells. After HTx, less than 0.25 donor $\mathrm{MHC}$ class $\mathrm{II}^{+}$cells/HPF were detected in the red pulp, periarteriolar lymphoid sheath (PALS), and marginal zone of the spleen, regardless of TAC administration (data not shown). In contrast, many more donor MHC class $\mathrm{II}^{+}$ cells were found in the recipient spleen after liver transplantation. At 1 and 3 days, the number and location of these cells was the same with or without TAC treatment. Donor class
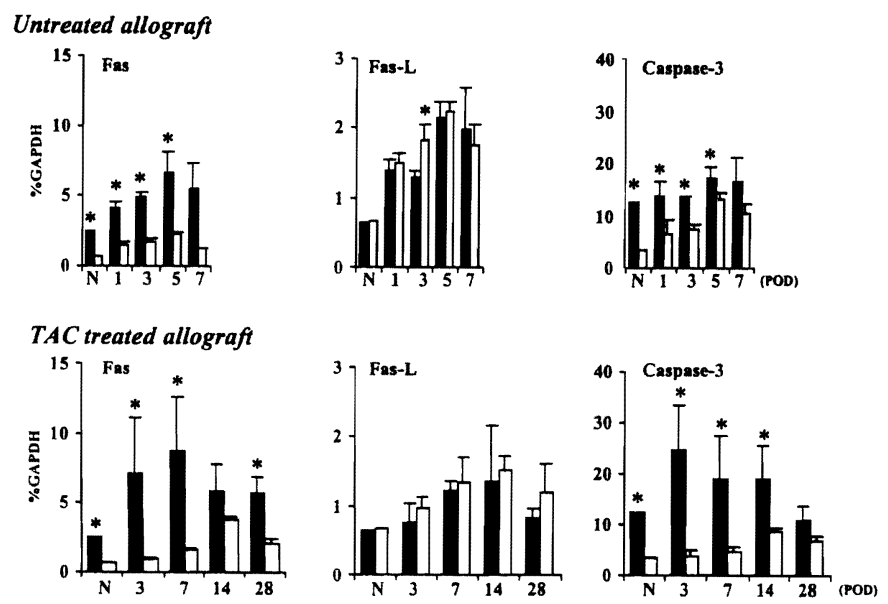

FIGURE 6. RPA of mRNA for Fas, Fas-L, and caspase-3 in heart (open bars) and liver allografts (black bars) without treatment (upper panels) or under a 28-day course of TAC (lower panels). $n=3-6$ at each time point: $* P<05$ (liver vs. heart).
(A) BrdU uptake
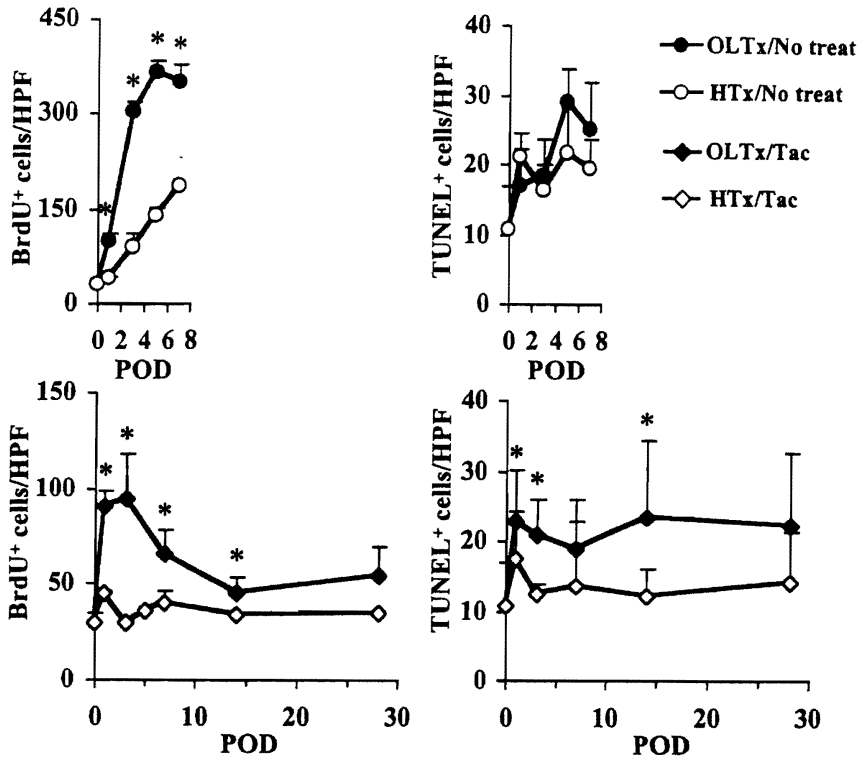

Figure 7. Numbers of (A) BrdU ${ }^{+}$and (B) TUNEL $^{+}$cells per high power field $(\times 400)$ in recipient spleen on different postoperative days (POD) after HTx and OLTx; compared with findings in allografts (Fig. 5). Recipients were either untreated (top) or treated with short course of TAC (bottom). Both $\mathrm{BrdU}^{+}$and TUNEL ${ }^{+}$cells increased in untreated recipients. Under TAC, liver recipients show sustained increases of proliferation and apoptosis. $n=3-6$ at each time point. $* P<0.05$ (liver vs. heart).
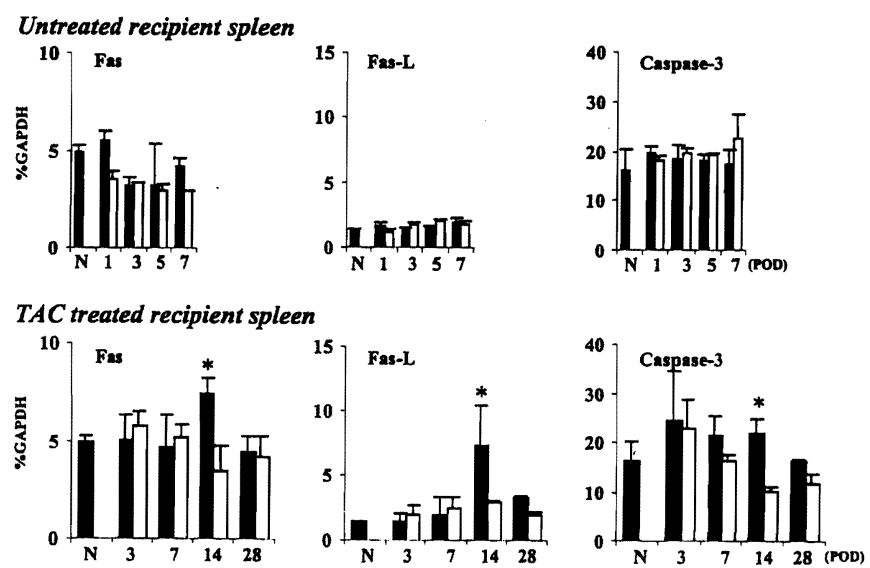

FIGURE 8. RPA of mRNA for apoptotic signals in the spleen of heart and liver recipients without treatment (top) or under a short course of TAC (bottom). Compare with findings in Figure 6. $n=3-6$ at each time point. $* P<0.05$ (liver vs heart).

$\mathrm{II}^{+}$cells disappeared from the spleen of untreated animals by 7 days. In TAC-treated liver recipients (Fig. 9), the mean numbers of donor $\mathrm{MHC}$ class $\mathrm{II}^{+}$cells were $13.0,11.8,1.7$, and 1.1 cells/HPF at $1,3,7$, and 14 posttransplant days, respectively.

The donor MHC class $\mathrm{II}^{+}$cells localized predominantly to the periphery of the splenic PALS and marginal zone by 1 day after transplantation although a small number was also found within the PALS. Donor MHC class $\mathrm{II}^{+}$cells disap- 


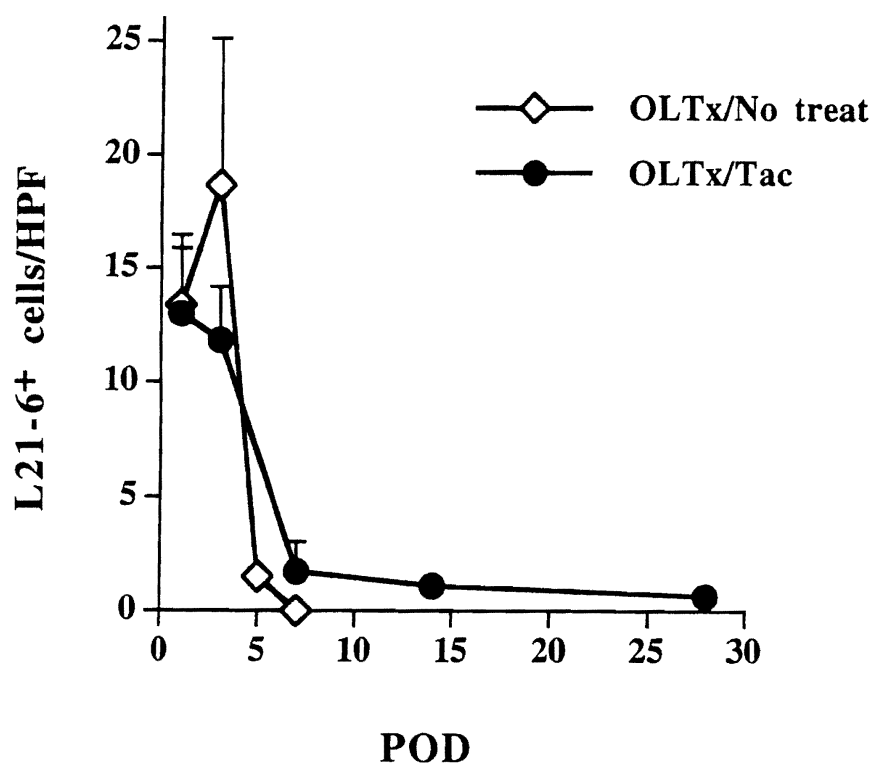

Figure 9. Number of donor (LEW) MHC class $\mathrm{II}^{+}\left(\mathrm{L21}^{+} \mathbf{6}^{+}\right)$ cells in the BN host spleen after liver transplantation. Far fewer donor $\mathrm{MHC}$ class $\mathrm{II}^{+}$cells are found after heart transplantation (23). Mean \pm SD of three to seven animals at each time point.

peared from the marginal zone during the next 7 days although a few persisted in the PALS for 28 days.

Double immune fluorescence. Double staining with $\mathrm{mAb}$ L21-6 and anti-rat IgM or OX33 (CD45RA) showed that L21- $6^{+} / \mathrm{IgM}^{+}$donor B cells and other donor MHC class $\mathrm{II}^{+}$ cells localized mainly to the B-cell follicle and marginal zone of the recipient spleen after OLTx (Fig. 10, A and B). Double staining for macrophages (ED1, ED2) excluded the possibility of significant donor macrophage migration to the recipient spleen (Fig. 10, C and D). The few donor MHC class $\mathrm{II}^{+}$cells localizing to $\mathrm{T}$ cell areas (mAb R7. $3^{+}, \alpha \beta \mathrm{TCR}^{+}$) (Fig. 10, E and $F$ ) were also positive for CD11c (8A2), indicative of donor MHC class $\mathrm{II}^{+} \mathrm{DC}$ (Fig. 10, G and H). Although expression of CD8 $\alpha$ correlates with differences in lineage origin and function activity of $\mathrm{DC}(27)$, only a few donor $\mathrm{DC}$ expressed CD8 $\alpha$. This suggests that donor $\mathrm{DC}$ migrating into the recipient spleen after OLTx are a mixture of "myeloid" and "lymphoid" DC (Fig. 10I).

\section{Flow Cytometry of Spleen Cells}

Because the foregoing studies were limited to donor MHC class $\mathrm{II}^{+}$cells, they grossly underestimated the total donor cell load delivered to the spleen. To obtain a rough estimate of the true migratory leukocyte traffic relative to the MHC class $\mathrm{II}^{+}$subset, spleen cell suspensions were analyzed by flow cytometry using antidonor/recipient MHC class I mAbs after both HTx and OLTx. With or without treatment, donor cells could not be reliably detected by flow cytometry in the recipient spleen at any time point after HTx (data not shown).

Without TAC treatment, donor cells disappeared from the spleens of liver recipients by 7 days. Under TAC, donor MHC class $\mathrm{I}^{+}$cells accounted for 1 to $5 \%$ of splenocytes between 1 to 14 days after OLTx (Fig. 11). The donor cells at 7 days in the treated animals were mainly $\alpha \beta \mathrm{TCR}^{+}(50-70 \%)$, but NK and $B$ cells also were identified.

\section{DISCUSSION}

It is known that donor passenger leukocytes leave the allograft after organ transplantation (28-30) and migrate preferentially at first to host lymphoid organs $(17,24,31,32)$. They induce an adaptive immune response that may proceed to variable degrees of apoptosis-associated (33) clonal exhaustion-deletion $(1-4,34)$, the maintenance of which is dependent on the continued presence of the mobile donor cells $(1,2)$. Survival of small numbers of these donor passenger leukocytes is facilitated by their secondary migration to "protected" nonlymphoid sites including the organ allograft (3537 ), from where they may pass back to host lymphoid organs and maintain the donor-specific clonal exhaustion-deletion induced at the outset $(1,2)$.

In this paradigm, the key event in determining immune responsiveness or nonresponsiveness to an organ is leukocyte migration and localization. Consequently, the variable posttransplant events are best understood in terms of dose and localization of the mobile antigen, and particularly the time during which this alloantigen is in host lymphoid organs ( 1 , 2). The serial changes in proliferation/apoptosis indices in our experiments suggest that the immune activation-dependent mechanisms that result in the evolution of variable levels of immunosuppression-assisted deletional tolerance and engraftment differ only in degree after liver and heart transplantation. The proliferation response induced by the highly tolerogenic liver exceeded that induced by the weakly tolerogenic heart. The differences in outcome were explicable by the far greater load of immunostimulatory passenger leukocytes contained in hepatic allografts, and by the persistence of more of these cells in the liver recipients.

In this interpretation, the changing cytokine profiles observed were downstream effects of unmodified or immunosuppression-altered immune activation, rather than implying any self-sustaining immunoregulatory role in organ engraftment of the cytokines per se, singly or in combination. One of the immune regulation hypotheses holds that the absence of the TH1 type cytokines (IL-2 and IFN $\gamma$ ) and the presence of TH2 type cytokines (IL-4 and IL-10) lead to the CR-free organ transplant acceptance $(38-40)$. This has not been supported by molecular studies of cytokine mRNA of human renal allografts or by observations in several animal models (41). We have suggested instead that alloengraftment is an active process whose perpetuation requires the persistence of donor leukocytes $(1,2)$.

Our specific question was whether there was any histopathological evidence in the host spleen suggesting a unique role of particular lineages of the donor leukocytes, either in eliciting rejection or inducing tolerance. The question was prompted in part by the results of a recent study by Ichikawa et al. (35) in which the percentages and lineages of donor leukocytes in cell suspensions prepared from test LEW heart allografts and host spleens were determined after their transplantation to drug-free $\mathrm{BN}$ recipients who had variably tolerized 100 days previously by LEW heart, bone marrow cell, or liver transplantation under the standard 28-day course of TAC. In these earlier studies, flow cytometry analyses and parallel histopathological-immunocytochemical findings showed that the failure of $\mathrm{CR}$ to develop in the 


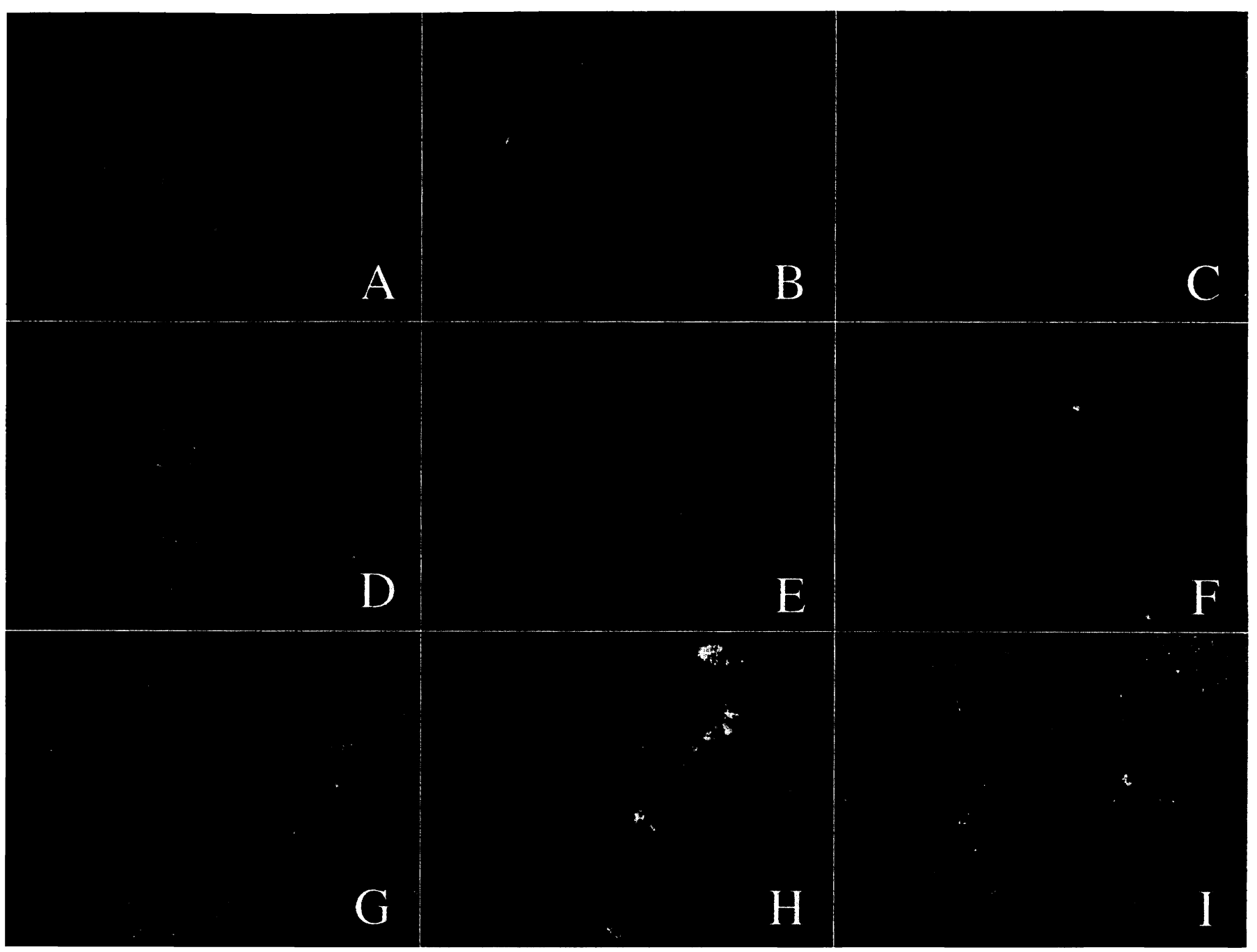

FIGURE 10. Immunofluorescence stain of donor MHC class $\mathrm{II}^{+}$cells. Double immunflourescence stain using $\mathrm{mAb}$ L21-6 (LEW MHC class II) in all panels with a variety of lineage-specific mAbs. Donor MHC class $\mathrm{II}^{+}$cells stained only with $\mathrm{L21-6}$ are red. Cells stained only with lineage specific mAb are green. Double-stained cells are yellow. (A) Rat IgM stain of B-cell follicle surrounded by marginal zone. The vacant area (right) is periarteriolar lymphoid sheath (PALS). Note the dense concentration of donor B cells (yellow) within the follicle, and a few probable DC (red) in the periphery of PALS $(\times 200)$. (B) Higher power of follicle-PALS junction shown in A $(\times 400)$. (C) ED1 single-stained macrophages (green) in the red pulp outside the periphery of the marginal zone with single-stained L21-6 ${ }^{+}$cells in the heart of the B-cell follicle $(\times 200)$. (D) ED2 single-stained macrophages (green) in the red pulp. The B-cell follicle has been moved more to the right than in $C(\times 200)$. (E) Single-stained $\alpha \beta$ TCR $^{+}$T cells (probably host) in PALS (right) with numerous L21-6 ${ }^{+}$(donor) B cells in the follicle and two L21-6 ${ }^{+}$cells (presumably DC) in PALS $(\times 200)$. (F) Higher power of $E$ showing the two probable DC in PALS $(\times 400)$. (G) Double-stained

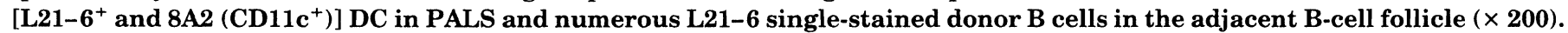
(H) Higher power of $G(\times 400)$. (I) A few double-stained cells $\left[\mathrm{L21}^{-6^{+}}\right.$and $\left.\mathrm{OX8}^{+}(\mathrm{CDB} \alpha)\right]$ thought to be lymphoid DC in the PALS with a few adjacent single-stained L21-6 ${ }^{+}$cells $(\times 200)$.

challenge hearts correlated more directly with the total quantity of donor leukocytes in the challenge cardiac allografts and the spleens of the primed host than with the small subset of $\mathrm{MHC}$ class $\mathrm{II}^{+}$donor leukocytes that included DC (35).

Because MHC class $\mathrm{II}^{+}$cells function as antigen presenting cells (APC) and because DC can prime $\mathrm{T}$ cells in vitro, it has been assumed that DC constitute the truly immunogenic subset of passenger leukocytes $(19-21,42)$. Neither our findings in the spleens of recipients of primary liver allografts nor the related observations of Ichikawa et al. (35) formally eliminate the possibility that donor DC play a crucial role in graft outcome. Our data are not consistent with a lineagespecific hypothesis to explain either organ rejection or alloengraftment. During the first 2 weeks after liver transplantation, donor cells accounted for 1 to $5 \%$ of the host spleen leukocytes. Most of these donor cells were class $\mathrm{II}^{-}$(that is, $50-70 \%$ were $\mathrm{T}$ cells). The smaller population of $\mathrm{MHC}$ class $\mathrm{II}^{+}$donor leukocytes was made up principally of B cells with only a very small proportion of myeloid/lymphoid DC.

Most of the donor B cells migrated to the B-cell areas of the recipient spleen where (as expected) direct contact and aggregation of host $\mathrm{T}$ cells around donor $\mathrm{B}$ cells could not be demonstrated by double labeling. The few donor DC were 

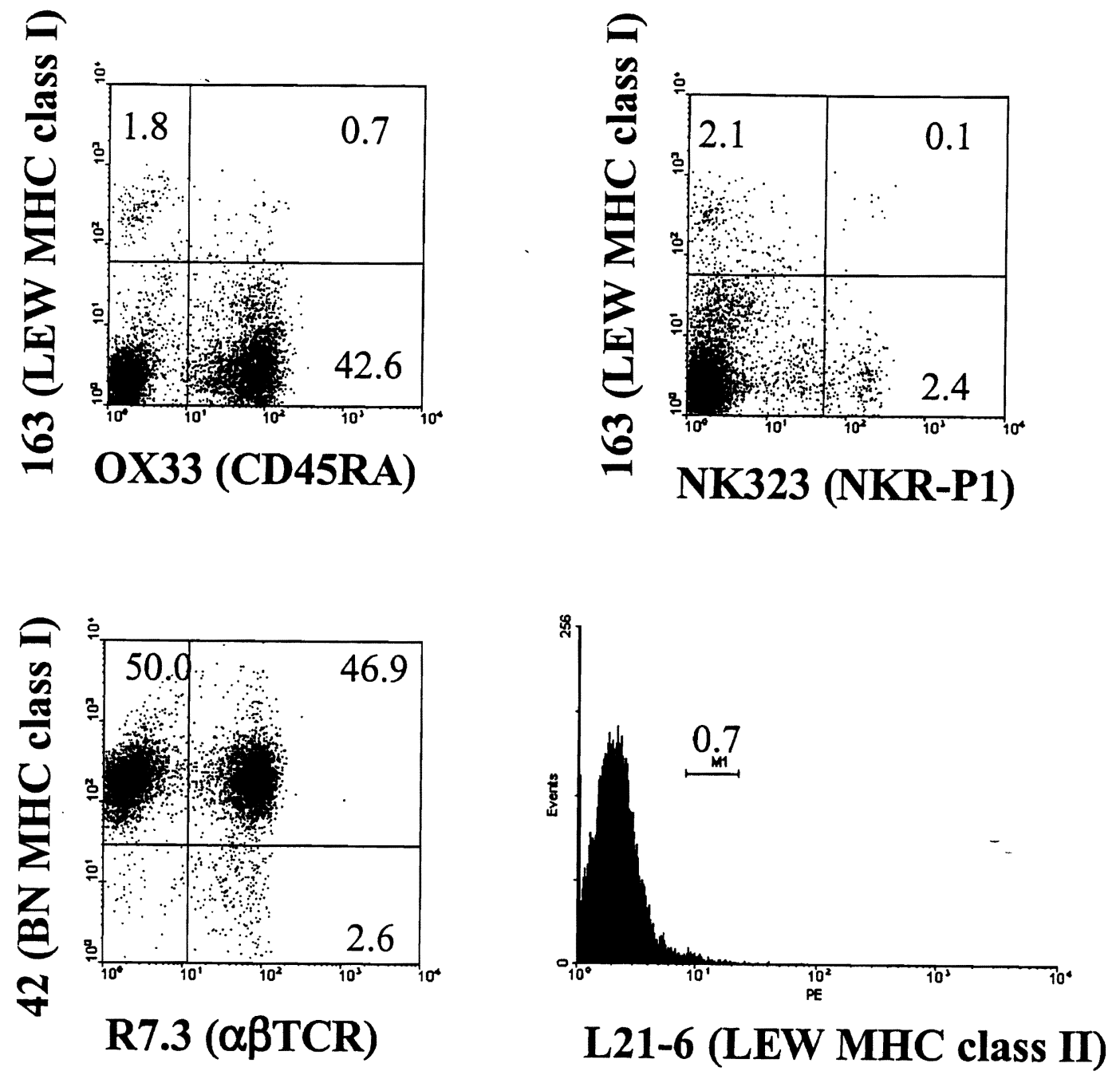

Figure 11. Two-color flow cytometric analysis of splenocytes using mAbs 163 (LEW MHC class I), 42 (BN MHC class I), and L21-6 (LEW MHC class II), and lineage-specific mAbs OX 33 (B cells), R7.3 ( $\alpha \beta$ TCR), and NK323 (NK cells). Splenocytes were obtained 7 days after LEW to BN OLTx under TAC immunosuppression. Representative experiment performed in four animals (see text).

limited to the splenic PALS, in contiguity with $\mathrm{T}$ cells (see Fig. 10). Despite their strict localization to the splenic $T$ cell area, it was not possible with our methodology to identify the aggregation of host $\mathrm{T}$ cells around donor $\mathrm{DC}$ that has been ascribed to "direct allorecognition" or "direct alloactivation." Thus, it remains unclear whether the donor MHC class $\mathrm{II}^{+}$ cells that reached splenic T-cell areas triggered host $\mathrm{T}$ cells directly or whether the alloantigens were presented as class II- (or class I) derived peptide to T cells via host APC by the classical "exogenous" indirect pathway (43) that has been increasingly associated with chronic (as opposed to acute) rejection $(19,20,44-46)$.

It is widely believed that allorecognition of and direct immune activation by highly immunogenic passenger leukocytes is responsible for acute rejection $(20,42,44,47)$. This hypothesis has been questioned by studies suggesting that acute rejection is largely, if not exclusively, by the indirect pathway (48-51). Whether and how peptide derived from the donor passenger leukocytes is captured and processed by the host APC via the indirect pathway is unclear.
Finally, the unique immunogenicity of the passenger leukocytes has been ascribed to special qualities of DC, e.g., the expression of MHC class II or costimulatory molecules such as B7 $(20,52,53)$. We studied the possibility that passenger leukocytes are immunogenic mainly because they can migrate to lymphoid organs although parenchymal cells ostensibly lack immunogenic properties simply because they are immobile and cannot reach these lymphoid destinations (2, 35 ). If this is correct, the quantity rather than the lineages of the passenger leukocytes is the key factor in initiating the immune activation that may lead to acute rejection, or proceed to clonal exhaustion-deletion and variable tolerance.

Acknowledgements. The authors thank Atsunori Nakao, Alison Logar, and Mike Tabacek for the expert technical support and expert organizational and secretarial assistance of Ms. Terry Mangan and Carla Forsythe in the preparation of this manuscript.

\section{REFERENCES}

1. Starzl TE, Zinkernagel RM. Antigen localization and migration in immunity and tolerance. N Engl J Med 1998; 339: 1905. 
2. Starzl TE, Zinkernagel RM. Regulation of transplant rejection, engraftment, and tolerance by antigen migration and localization: an historical perspective. Nature Reviews. Immunology 2001; 1: 233.

3. Starzl TE, Demetris AJ, Murase N, Ildstad S, Ricordi C, Trucco M. Cell migration, chimerism, and graft acceptance. Lancet 1992; 339: 1579.

4. Starzl TE, Demetris AJ, Trucco M, et al. Cell migration and chimerism after whole-organ transplantation: The basis of graft acceptance. Hepatology 1993; 17: 1127

5. Murase N, Starzl TE, Tanabe M, et al. Variable chimerism, graft-versushost disease, and tolerance after different kinds of cell and whole organ transplantation from Lewis to brown Norway rats. Transplantation. 1995; 60: 158.

6. Calne RY, Sells RA, Pena JR, et al. Induction of immunological tolerance by porcine liver allografts. Nature 1969; 223: 472 .

7. Kamada N, Brons G, Davies HS. Fully allogeneic liver grafting in rats induces a state of systemic nonreactivity to donor transplantation antigens. Transplantation 1980; 29: 429.

8. Corry RJ, Winn HJ, Russell PS. Primary vascularized allografts of hearts in mice. The role of $\mathrm{H}-2 \mathrm{D}, \mathrm{H}-2 \mathrm{~K}$ and non- $\mathrm{H}-2$ antigens in rejection. Transplantation 1973; 16: 343 .

9. Russell PS, Chase CM, Colvin RB, Plate JMD. Kidney transplants in mice: an analysis of the immune status of mice bearing long-term H-2 incompatible transplants. J Exp Med 1978; 147: 1449.

10. Murase N, Demetris AJ, Kim DG, Todo S, Fung JJ, Starzl TE. Rejection of the multivisceral allografts in rats: A sequential analysis with comparison to isolated orthotopic small bowel and liver grafts. Surgery 1990; 108: 880 .

11. Qian S, Demetris AJ, Murase N, Rao AS, Fung JJ, Starzl TE. Murine liver allograft transplantation: Tolerance and donor cell chimerism. Hepatology 1994; 19: 916.

12. Wood K, Sachs DH. Chimerism and transpantation tolerance: cause and effect. Immunol Today 1996; 17: 584.

13. Wekerle T, Sykes M. Mixed chimerism as an approach for the induction of transplantation tolerance. Transplantation 1999; 68: 59.

14. Schlitt HJ, Hundrieser JH, Ringe B, Pichlmayr R. Donor-type microchimerism associated with graft rejection eight years after liver transplantation. N Engl J Med 1994; 330: 646.

15. Ko S, Deiwick A, Jager MD, et al. The functional relevance of passenger leukocytes and microchimerism for heart allograft acceptance in the rat. Nat Med 1999; 5: 1292.

16. Demetris AJ, Murase N, Starzl TE. Donor dendritic cells after liver and heart allotransplantation under short-term immunosuppression. Lancet 1992; 339: 1611.

17. Demetris AJ, Murase N, Fujisaki S, Fung JJ, Rao AS, Starzl TE. Hematolymphoid cell trafficking, microchimerism, and GVHD reactions after liver, bone marrow, and heart transplantation. Transplant Proc 1993; 25: 3337.

18. Lu L, Rudert WA, Qian S, et al. Growth of donor-derived dendritic cells from the bone marrow of murine liver allograft recipients in response to granulocyte/macrophage colony-stimulating factor. J Exp Med 1995; 182: 379

19. Lechler RI, Batchelor JR. Restoration of immunogenicity to passenger cell-depleted kidney allografts by the addition of donor-strain dendritic cells. J Exp Med 1982; 155: 31.

20. Lechler R, Ng WF, Steinman RM. Dendritic cells in transplantationfriend or foe? Immunity 2001; 14: 367

21. Steinman RM. The dendritic cell system and its role in immunogenicity. Annu Rev Immunol 1991; 9: 271.

22. Thomson AW, Lu L, Murase N, Demetris AJ, Rao AS, Starzl TE. Microchimerism, dendritic cell progenitors and transplantation tolerance. Stem Cells 1995; 13: 622

23. Demetris AJ, Murase N, Ye Q, et al. Analysis of chronic rejection and obliterative arteriopathy. Possible contributions of donor antigen-presenting cells and lymphatic disruption. Am J Pathol 1997; 150: 563.

24. Demetris AJ, Qian S, Sun H, et al. Early events in liver allograft rejection. Delineation of sites of simultaneous intragraft and recipient lymphoid tissue sensitization. Am J Pathol 1991; 138: 609.

25. Yagihashi A, Takahashi S, Murase N, Starzl TE, Iwaki Y. A monoclonal antibody (L21-6) recognizing an invariant chain expressed on the cell surface in rats with the exception of the BN (RT1n): a study of tissue and strain distributions. Transplant Proc 1995; 27: 1519.

26. Gill TJ, Kunz HW, Misra DN, Hassett AL. The major histocompatibility complex of the rat. Transplantation 1987; 43: 773.
27. Vremec D, Zorbas M, Scollay $R$, et al. The surface phenotype of dendritic cells purified from mouse thymus and spleen: Investigation of the CD8 expression by a subpopulation of dendritic cells. J Exp Med 1992; 176 47.

28. Porter KA. Pathology of the orthotopic homograft and heterograft. In Starzl TE, ed. Experience in hepatic transplantation. Philadelphia: WB Saunders, 1969; 464

29. Murase N, Demetris AJ, Matsuzaki T, et al. Long survival in rats after multivisceral versus isolated small bowel allotransplantation under FK 506. Surgery 1991; $110: 87$.

30. Iwaki Y, Starzl TE, Yagihashi A, et al. Replacement of donor lymphoid tissue in human small bowel transplants under FK 506 immunosuppression. Lancet 1991; 337: 818

31. Nemlander A, Soots A, von Willebrand E, Husberg B, Hayry P. Redistribution of renal allograft-responding leukocytes during rejection. II Kinetics and specificity. J Exp Med 1982; 156: 1087.

32. Larsen CP, Morris PJ, Austyn JM. Migration of dendritic leukocytes from cardiac allografts into host spleens. A novel route for initiation of rejection. J Exp Med 1990; 171: 307

33. Qian S, Lu L, Fu F, et al. Apoptosis within spontaneously accepted mouse liver allografts: evidence for deletion of cytotoxic $\mathrm{T}$ cells and implications for tolerance induction. J Immunol 1997; 158: 4654.

34. Bishop AG, Sun J, Sheil AGR, McCaughan GW. High-dose/activationassociated tolerance. Transplantation 1997; 64: 1377.

35. Ichikawa N, Demetris AJ, Starzl TE, et al. Donor and recipient leukocytes in organ allografts of recipients with variable donor-specific tolerance: with particular reference to chronic rejection. Liver Transplant 2000; 6: 686.

36. Terakura M, Murase N, Demetris AJ, Ye Q, Thomson A, Starzl TE. Lymphoid/non-lymphoid compartmentalization of donor leukocyte chimerism in rat recipients of heart allografts, with or without adjunct bone marrow. Transplantation 1998; 66: 350 .

37. Sakamoto T, Ye Q, Lu L, Demetris AJ, Starzl TE, Murase N. Donor hematopoietic progenitor cells in non myeloablated rat recipients of allogeneic bone marrow and liver grafts. Transplantation 1999; 67: 833.

38. Mosmann TR, Moore KW. The role of IL-10 in crossregulation of TH1 and TH2 responses. Immunol Today 1991; 12: A49-53.

39. Nickerson P, Steurer W, SteigerJ, Zheng X, Steele AW, Strom TB. Cytokines and the Th1/Th2 paradigm in transplantation. Curr Opin Immunol 1994; 6: 757.

40. Goldman M, Velu T, Grunfield J-P, Bach JF, Kreis H, Maxwell MH. Advances in Nephrology. St. Louis: Mosby Year Book, Inc. 1995; 79.

41. Suthanthiran M. Molecular exploration of the anti-allograft response. Transplant Immunol Lett 13:1997; 4: 11

42. Steinman RM, Cohn ZA. Identification of a novel cell type in peripheral lymphoid organs of mice. I. Morphology, quantitation, tissue distribution. J Exp Med 1973; 137: 1142.

43. Zinkernagel RM, Doherty PC. Restriction of in vitro $\mathrm{T}$ cell-mediated cytotoxicity in lymphocytic choiromeningitis within a syngeneic or semiallogeneic system. Nature 1974; 248: 701.

44. Shoskes DA, Wood KJ. Indirect presentation of MHC antigens in transplantation. Immunol Today 1994; 15: 32

45. Womer KL, Vella JP, Sayegh MH. Chronic allograft dysfunction: mechanisms and new approaches to therapy. Semin Nephrol 2000; 20: 126.

46. Gould DS, Auchincloss H Jr. Direct and indirect recognition: the role of MHC antigens in graft rejection. Immunol Today 1999; 20: 77.

47. Rogers NJ, Lechler RI. Allorecognition. Am J Transplant 2001; 1: 97

48. Ochsenbein AF, Sierro S, Odernatt B, et al. Roles of tumor-localization, second signals, and cross-priming in cytotoxic T-cell induction. Nature 2001; 411: 1058 .

49. Smith CR, Jaramillo A, Liu W, et al. CD4 + T cell recognition of a single discordant HLA-A2-transgenic molecule through the indirect antigen presentation pathway induces acute rejection of murine cardiac allografts. Transplantation 2001; 71: 1640.

50. Sims TN, Afrouzian M, Urmson J, Zhu LF, Halloran PF. The role of the class II transactivator (CIITA) in MHC class I and II regulation and graft rejection in kidney. Am J Transplant 2001; 1: 211

51. Jurcevic S, Chandler P, Sacks SH, Simpson E. Rapid rejection of HLA-A2 Transgenic skin graft due to indirect allorecognition. Transplantation 2001; 72: 994

52. Matzinger P. Tolerance, danger, and the extended family. Annu Rev Immunol 1994; 12: 991.

53. Cohn M. The wisdom of hindsight. Annu Rev Immunology 1994; 12: 1. 